\title{
Effect of Different Sterilization Methods on Contamination and Viability of Nodal Segments of Cestrum nocturnumL
}

\author{
Sameer N. Mahmoud ${ }^{1}$, Nabeel K. Al-Ani ${ }^{2}$ \\ ${ }^{1}$ Biotechnology Research Center/ Al-Nahrain University \\ ${ }^{2}$ College of Applied Biotechnology/ Al-Nahrain University
}

\begin{abstract}
Surface sterilization is a vital step in preparation of healthy and viable explants in tissue culture because plants in the field are highly exposed to microbial contamination. Most surface contaminants, such as bacteria and fungi, can be eliminated by surface sterilization with a suitable sterilizing agent. In this study three surface sterilizing agents were used: plant preservative mixture (PPM), mercuric chloride $\left(\mathrm{HgCl}_{2}\right)$ and sodium hypochlorite (NaOCl). Different concentrations and time exposure were tested for decontamination and shoot development of the nodal segments of Cestrum nocturnumL. in vitro. The results showed that among the three sterilizing agents used in this study, PPM treatment at concentrations (4,6\%) for 4 hours of constant shaking were effective in terms of decontamination percentage (100), survival and viability of the nodal segments and shoot development percentage (70\%). The PPM treatment at all concentrations (1,2,4,6\%) for 12 hours of constant shaking gave all dead nodal segments, thus viability of the nodal segments was affected. Sterilization with $\mathrm{HgCl}_{2}$ at all concentrations $(0.05,0.1,0.2 \%)$ for 7 minutes of continuous rinsing showed good results in terms of decontamination (90-100\%) and survival and shoot development percentages (50-60\%), while ( $\mathrm{NaOCl)}$ at higher concentration of (50\%) for 5 minutes of continuous rinsing showed satisfactory result of viability and shoot development (50\%). The numbers and percentages of contaminated and survived nodal segments were recorded after 30 days. All Viable nodal segments developed to shoots. It had been concluded that the best surface sterilization agent was PPM.
\end{abstract}

Keywords: Cestrum nocturnum, surface sterilization, PPM, mercuric chloride, sodium hypochlorite, nodal segments, viability and shoot development

\section{INTRODUCTION}

Cestrumnocturnum L.commonly known as night-blooming Jessamine or night queen.Itis a perennial woody bush with glossy, smooth, simple leaves, vine-like stems and greenish, creamy white tubular flowers. C. nocturnum belongs to the family Solanaceae (the potato family)[1]. It is native to Central and South America and the West Indies. The farmers cultivate it in parts of the United States of America and other parts of the world for perfumes and essential oils and in subtropical regions as an ornamental plant for its flowers at night that are heavily perfumed[1]. C. nocturnum is probably the world's strongest smelling plant, the scent can reach up to 165 feet $(50 \mathrm{~m})$ away from the location of the plant[1].The C.nocturnum has several pharmacological activities such as antimicrobial, larvicidal, antimalarial and antioxidant. The leaves of the plant have been shown significant bactericidal activity [2] and Local anesthetic effect is also confirmed [3].

Plants growing in the external environments contaminated with microorganisms. Microbial contamination of plant affect adversely in plant tissue culture. These microbes can compete for nutrients, increase culture mortality and may result in variable growth, tissue necrosis, reduced shoot proliferation and rooting [4]. These contaminants are not always seen during early culture stages; some internal contaminants become visible at later subcultures and are difficult to eliminate[5] .These external contaminants easily removed by washing in running water for 30-90 minutes and disinfecting with surface sterilizing agents such as, fungicides, alcohols, $\mathrm{HgCl}_{2}$ and $\mathrm{NaOCl}$. Some of these sterilizing agents found effective for the disinfection of explants obtained from field-grown plants other is not. Utilizing a proper and precise sterilization procedure in tissue culture techniques can be vital to save time and effort. However, the explants must be viable after sterilizing. Various sterilizing agents used to decontaminate plant tissues. Some of these agents are toxic to the plant tissues, therefore suitable concentration, exposure duration of the explants to the various sterility and the sequences of using these sterility have to be standardized to minimize explants injury and achieve better survival[6]. 
Plant preservative mixture $\mathrm{PPM}^{\mathrm{TM}}$ is a broad-spectrum biocide. PPM used as an alternative to conventional antibiotics and fungicides as well as the common sterilizing agents to control contamination in plant tissue culture. PPM controls microbes by penetrating the microbial cell wall and inhibiting several essential enzymes in the citric acid cycle and electron transport chain (PCT (1998). PPM is a good product, but it has to select the precise concentration in relation to the plant species. The sterilizing procedure could change depending on species and season of collection. Mercuric chloride $\mathrm{HgCl}_{2}$ is extremely toxic to both plants and humans and has to be disposed of with care. Since mercury is aphyto-toxic, it is important that many washes done to remove all traces of the mineral from the plant material. Sodium hypochlorite $\mathrm{NaOCl}$ is a common choice for surface sterilization. It is available as commercial bleach product such as Fast and Clorox and can be diluted to proper concentrations. Explants immersed in this solution for 5-20 minutes. A balance between concentration and time must be verified for each type of explants because of its phytotoxicity. Ethanol is a strong sterilizing agent but extremely phyto-toxic. Thus, explants usually exposed to it for only seconds or minutes. The more tender the tissue, the more it will be damaged by alcohol. Tissues such as seeds, dormant buds, or unopened flower buds can be treated for longer periods of time with alcohol since the tissue that will be explanted or will develop is within the structure that is being surface sterilized. Generally $70 \%$ ethanol is used as pre-treatment with other sterilizing agent. In general, ethanol sterilizes the surface, but it can dehydrate the tissues. Mercuric chloride is very strong and very dangerous and toxic to plant and human but is effective against bacterial contamination. PPM is none toxic agent.

The present study aimed to present an effective method for plant explants sterilization. In this study PPM with concentrations of 1, 2, 4, 6\% and time exposure of 4 and $12 \mathrm{~h}$ were employed to evaluate for their sterilizing effect. Comparison was made between PPM and the two important sterilizing agents; mercuric chloride $\left(\mathrm{HgCl}_{2}\right.$ ) and sodium hypochlorite $(\mathrm{NaOCl})$.

\section{MATERIALS AND MethodS}

The Cestrum nocturnum shoots obtained from local garden in Baghdad in March-April. Nodal segments excised from young and healthy shoots. Before sterilization, nodal segments cut to $1-2 \mathrm{~cm}$ in size from the top parts of the shoots and all leaves removed. In all treatments, the nodal segments washed under running tap water for one hour to remove microorganisms and dust particles from the surface. These nodal segments then, exposed to surface sterilization. Three sterilizing agents, plant preservative mixture (PPM), mercuric chloride $\left(\mathrm{HgCl}_{2} \mathrm{w} / \mathrm{v}\right)$ and sodium hypochloride $(\mathrm{NaOClv} / \mathrm{v})$ (commercial brand FAST) which contain $(6.2 \%) \mathrm{NaOCl}$ as active agent with varying concentrations and time of exposure were used to test for decontamination. Murashige and Skoog (MS1962) basal medium that supplemented with appropriate plant growth regulators (6-benzylaminopurine (BAP) $(5 \mathrm{mg} / \mathrm{l})$ and 2,4-dichlorophenoxyacetic acid $(2,4-\mathrm{D})(3 \mathrm{mg} / \mathrm{l}))$ were applied for shoot initiation in vitro. Nodalsegments cultured on MS medium in universal tubes and observing them in 30 days. Ten replicates used for each sterilization treatment, where each tube contained one nodal segment. The $\mathrm{pH}$ of the medium was adjusted to 5.8 with $1 \mathrm{~N} \mathrm{NaOH}$ or $1 \mathrm{~N} \mathrm{HCl}$ and afterward autoclaved at $121^{\circ} \mathrm{Cfor}$ $20 \mathrm{~min}$. The cultures were maintained in growth incubator at $25 \pm 1^{\circ} \mathrm{C}$ for 30 days, with a $16 / 8 \mathrm{~h}$ light/dark photoperiod under an illumination of 1000 Lux photosynthetic photonflux intensity provided by cool- white fluorescent light. Ventilation and moisture also maintained properly in growth incubator throughout the investigation. The ends of sterilized nodal segments were trimmed to remove sterilizing agent affected parts/brown parts. After 30 days the percentage of contaminated, survived and dead nodal segments were recorded.

Nodal segments were sterilized by PPM with four concentrations $(1,2,4,6 \%)$ for two time duration 4 and 12 hours in constant shaking, $\mathrm{HgCl}_{2}$ with three concentrations $(0.05,0.1,0.2 \%)$ for $7 \mathrm{~min}$ and $\mathrm{NaOCl}$ with three concentrations $(10,30,50 \%)$ for $5 \mathrm{~min}$. The nodal segments then, dried inside the laminar airflow and finally cultured on the MS basal media in universal tubes. The nodal segments that sterilized by PPM were first agitated for 4or 12 hour with four different concentration $(1,2,4$, $6 \%$ ). Next, the sterilizing solutions removed by rinsing with sterile distilled water 4-5 times for $2 \mathrm{~min}$ each time. The procedure adopted with PPM sterilizing agent was that explained in the instruction by the manufacturer (company) of the product. The nodal segments that were sterilized by sodium hypochlorite $(\mathrm{NaOCl})$, first immersed in $70 \%$ ethanol for one minute, afterward exposed to each of the $\mathrm{NaOCl}$ concentrations $(10,30,50 \%)$ for $5 \mathrm{~min}$ with few drops of Tween 80 were added to the solutions. The use of ethanol and $\mathrm{NaOCl}$ is to reduce contamination and by adding the Tween 80 is to enhance the coverage of the solution on all explants. 
Effect of Different Sterilization Methods on Contamination and Viability of Nodal Segments of Cestrum nocturnum L.

The sterilized nodal segments were then rinsed thoroughly with sterile distilled water 3-4 times for 2 minutes each time to remove the disinfectant completely. Nodal segments were also surface sterilized with $(0.05,0.10,0.20 \%) \mathrm{HgCl}_{2}$ concentration for $7 \mathrm{~min}$ and then thoroughly rinsed with sterile distilled water 3-4 times for 2 min each time to remove the disinfectant completely. In all treatments, 10 replicates made for each concentration.

\section{RESUlts AND DisCuSSION}

Table1. Sterilizing agents in different concentrations with varying time duration for nodal segments of $C$. nocturnum

\begin{tabular}{|c|c|c|}
\hline Sterilizing agent & Concentration \% & Time of exposure \\
\hline \multirow{4}{*}{ PPM } & 1 & \multirow{4}{*}{4 hours of constant shaking } \\
\hline & 2 & \\
\hline & 4 & \\
\hline & 6 & \\
\hline \multirow[t]{4}{*}{ PPM } & 1 & \multirow[t]{4}{*}{12 hours of constant shaking } \\
\hline & 2 & \\
\hline & 4 & \\
\hline & 6 & \\
\hline \multirow[t]{3}{*}{$\mathbf{H g C l}_{2}$} & 0.05 & \multirow[t]{3}{*}{7 minutes of continuous rinsing } \\
\hline & 0.1 & \\
\hline & 0.2 & \\
\hline \multirow[t]{3}{*}{$\mathrm{NaOCl}$} & 10 & \multirow[t]{3}{*}{5 minutes of continuous rinsing } \\
\hline & 30 & \\
\hline & 50 & \\
\hline
\end{tabular}

Table2. Results of PPM treatment in constant shaking for 4 h after 30 days

\begin{tabular}{|l|l|l|l|l|}
\hline $\begin{array}{c}\text { Concentration } \\
\mathbf{\%}\end{array}$ & $\begin{array}{c}\text { Total } \\
\text { no. }\end{array}$ & Contamination \% & $\begin{array}{c}\text { No. of shoot } \\
\text { development }\end{array}$ & $\begin{array}{c}\text { Survival and Shoot development } \\
\mathbf{\%}\end{array}$ \\
\hline $\mathbf{1}$ & 10 & 60 & 1 & 10 \\
\hline $\mathbf{2}$ & 10 & $40^{*}$ & 7 & 70 \\
\hline $\mathbf{4}$ & 10 & 0.0 & 7 & 70 \\
\hline $\mathbf{6}$ & 10 & 0.0 & 7 & 70 \\
\hline
\end{tabular}

* one contaminated tube (with one nodal segment) developed to shoot

Table3. Results of PPM treatment in constant shaking for $12 \mathrm{~h}$ after 30 days

\begin{tabular}{|l|l|l|l|l|}
\hline $\begin{array}{c}\text { Concentration } \\
\%\end{array}$ & Total no. & $\begin{array}{c}\text { Contamination } \\
\%\end{array}$ & $\begin{array}{c}\text { No. of shoot } \\
\text { development }\end{array}$ & $\begin{array}{c}\text { Survival and Shoot } \\
\text { development \% }\end{array}$ \\
\hline $\mathbf{1}$ & 10 & 20 & 0.0 & 0.00 \\
\hline $\mathbf{2}$ & 10 & 0.0 & 0.0 & 0.00 \\
\hline $\mathbf{4}$ & 10 & 0.0 & 0.0 & 0.00 \\
\hline
\end{tabular}

Table4. Results of $\mathrm{HgCL} 2$ treatment after 30 days

\begin{tabular}{|l|l|l|l|l|}
\hline $\begin{array}{c}\text { Concentration } \\
\text { \% }\end{array}$ & $\begin{array}{c}\text { Total } \\
\text { no. }\end{array}$ & Contamination \% & $\begin{array}{c}\text { No. of shoot } \\
\text { development }\end{array}$ & $\begin{array}{c}\text { Survival and Shoot } \\
\text { development \% }\end{array}$ \\
\hline $\mathbf{0 . 0 5}$ & 10 & 0.0 & 5 & 50 \\
\hline $\mathbf{0 . 1}$ & 10 & 10 & 6 & 60 \\
\hline $\mathbf{0 . 2}$ & 10 & 0.0 & 5 & 50 \\
\hline
\end{tabular}

Table5. Results of $\mathrm{NaOCl}$ treatment after 30 days

\begin{tabular}{|l|l|l|l|l|}
\hline $\begin{array}{c}\text { Concentration } \\
\mathbf{\%}\end{array}$ & $\begin{array}{c}\text { Total } \\
\text { no. }\end{array}$ & Contamination\% & $\begin{array}{c}\text { No. of shoot } \\
\text { development }\end{array}$ & $\begin{array}{c}\text { Survival and Shoot } \\
\text { development \% }\end{array}$ \\
\hline $\mathbf{1 0}$ & 10 & 40 & 1 & 10 \\
\hline $\mathbf{3 0}$ & 10 & 30 & 3 & 30 \\
\hline $\mathbf{5 0}$ & 10 & 30 & 5 & 50 \\
\hline
\end{tabular}

Table (1) showed the three sterilizing agents that used to sterilize the nodal segments of the plant Cestrum nocturnum $\mathrm{L}$. with different concentrations and time of exposure. The results in table (2) 
showed that contamination decreased with an increase in PPM concentration, and shoot development increased with the increased of the PPM concentration. Results also, showed that at concentrations $(4,6 \%)$ PPM for 4 hour of constant shaking demonstrated the best decontamination and viability of the nodal segments and shoot development. At these concentrations, $100 \%$ percentage of healthy nodal segments and high survival and viable percentage of nodal segments that developed to shoots (70\%) were achieved, though the concentration (2\%) also gave (70\%) percentage of viable nodal segments that developed to shoots but showed (40\%) percentage of contamination. The PPM treatment for 12 hour of constant shaking showed the worst results at all concentrations $(1,2,4,6 \%)$. Data revealed that all nodal segments in this treatment recorded dead (100\%). The death of nodal segments may be attributed to the phytotoxicity of the PPM solution. The long exposure of the nodal segments to PPM solution may also be toxic to the explants as showed in table (3). Nevertheless, the procedure adopted by [7]to sterilize Arabidopsis thaliana seeds, using an overnight incubation with 4\% PPM, and the addition of $0.05 \%$ PPM to the medium did not produce any negative effects. The differences in resultscould be explained by the fact that the viability of the explants may depend on the tissue type and nature of the explants, which differ in their sterilization procedure requirements. In addition, several studies demonstrated the positive effect of PPM to control the contamination and showed the importance of using PPM at a proper concentration, which indicated to be different depending on the plant species since the use of PPM at relatively high concentration, could have negative effects on the development of plant tissue.

In this study, PPM was used for surface sterilization, rather than as an addition to the MS medium.PPM is a broad-spectrum agent and effective against microorganism infection when used for surface sterilization or as medium component. Very few experiments carried out using surface sterilization of PPM with plant explants and most conducted on seeds. Results of our experiments at PPM concentrations $(4,6 \%)$ for 4 hours of constant shaking were effective in terms of decontamination and shoot development percentages. However,[8] who used PPM as surface sterilization against explants obtained from naturally field grown A. densiflora and incubated for 20 min in PPM concentration reported that successful callus development occurred at up to $3 \%$ concentration of PPM, but the callus initiation rate decreased at 4\% PPM. They also showed that PPM concentrations at $(2-3 \%)$ were more effective at reducing contamination of A. densifloraexplants, specifically on shoot explants, than the tested antibiotic-antimycotic mixture. On the other hand results obtained by $[9,10]$ proposed that seed may be sterilized at various concentrations of PPM, depending on the plant species. [11] also reported that PPM could prevent microbial contamination in cucumber seed tissue culture. More experiments carried out using PPM as an addition to the medium. [12] showed that using the PPM can effectively control contamination in the cauliflower micro-shoot micropropagation system. The use of $0.5 \mathrm{ml} / \mathrm{l} \mathrm{PPM}$ added to the culture medium and $1 \mathrm{ml} / \mathrm{l} \mathrm{PPM}$ in the blending medium found to be optimal for controlling the contamination without causing a reduction in the effectiveness of the culture system. They also found that lower concentrations of PPM increased the number but reduced the viability of micro-shoots produced.[13] showed that the addition of $5 \mathrm{ml} / \mathrm{l}$ of PPM to the medium was effective in preventing the contamination of explants obtained from greenhouse and field grown citrus trees, previously sterilized by the usual surface sterilization methods. [14] also indicated the importance of PPM to control the contamination in brasicca's culture media.

The $\mathrm{HgCl}_{2}$ treatment showed effective decontamination results at all concentrations with (90-100\%) percentage of healthy nodal segments. At concentrations $(0.05,0.2 \%)$, the $\mathrm{HgCl}_{2}$ gave complete percentage of decontamination (100\%) and survival and viable nodal segments and shoot development percentage (50\%), whereas, at concentration $(0.1 \%)$ it gave $(90 \%)$ decontamination percentage and $(60 \%)$ of viable nodal segments and shoot development (table 4). The $\mathrm{NaOCl}$, which is a common disinfectant in tissue culture, also showed satisfactory result. The lower concentration $(10 \%)$ showed higher percentage of contamination $(40 \%)$ and lower percentage of survived nodal segments $(10 \%)$. However by increasing the concentration to $(50 \%), \mathrm{NaOCl}$ gave less percentage of contamination $(30 \%)$ and more survival and viable nodal segment percentages that developed to shoots $(50 \%)$ as illustrated in table (5). Both $\mathrm{HgCl}_{2}$ and $\mathrm{NaOCl}$ are toxic to the plant tissues, thus, proper concentrations of these sterilizing agents should be carefully selected. Here it observed that some nodal segments did not survive, it was probably due to damages occurred during sterilization procedure and/or due to damaged explants during excision. $\mathrm{NaOCl}$, as weak/or mild sterilizing agent, should be used in higher percentage to control contamination, however, $\mathrm{HgCl}_{2}$, which mainly has bactericidal action, was more effective and showed better decontamination percentages. The results of 
the experiments revealed that $\mathrm{HgCl}_{2}$ showed good sterilization effect at all tested concentrations. [12] used $\mathrm{HgCl}_{2}$ at concentration of $0.1 \%$ for 5 min which resulted in minimal phytotoxicity to shoot tip explants and presented acceptable control of contamination. However, $\mathrm{HgCl}_{2}$ was phyto-toxic to petiole explants. In these experiments, $\mathrm{HgCl}_{2}$ showed better sterilization effect than $\mathrm{NaOCL}$, which is in agreement with our results, though the duration of exposure differed. Experiments achieved by [15] showed that among the three sterilizing agents used to sterilize Aconitum heterophyllum nodal segments, $\mathrm{HgCl}_{2}, \mathrm{NaOCl}$ and $\mathrm{H}_{2} \mathrm{O}_{2}$, the treatment with $0.1 \% \mathrm{HgCl}_{2}$ for 5 min gave $100 \%$ healthy shoots, though they indicated that increasing concentration and time of exposure to $\mathrm{HgCl}_{2}$ gave more dead shoots. The present experimental result is also in accordance with[16] who found that among the three disinfectants used, the $\mathrm{HgCl}_{2}$ was better than $\mathrm{NaOCl}$ and $\mathrm{H}_{2} \mathrm{O}_{2}$ for surface sterilization of Pinelliaternata(Thunb.) Breit.[17] showed that sterilization with $0.1 \% \mathrm{HgCl}_{2}$ for 4 min is effective for disinfecting the field grown strawberry explants intended for in vitro culture, the $\mathrm{HgCl}_{2}$ treatment resulted in maximum percentage of explants survival. However, here results are not in accordance with [18] who showed that $\mathrm{NaOCl}$ was better sterilizing agent in treating potato sprout. They used two sterilizing agents, $\mathrm{NaOCl}(1 \%)$ and $\mathrm{HgCl}_{2}(0.1 \%)$ with three time duration 2, 5 and 8 minutes, and found that $\mathrm{NaOCl}$ for 8 minute was better for controlling the infection and had not any adverse effect on explants even in long duration. On the other hand,[19]reported that both sterilizing agents, $\mathrm{HgCl}_{2}$ and $\mathrm{NaOCl}$, were effective in making clean explants of Kinnow tree. Nevertheless, [20]showed treatment with sodium hypochlorite $(\mathrm{NaOCl})$, calcium hypochlorite $\mathrm{Ca}(\mathrm{ClO})_{2}$ and $\left(\mathrm{HgCl}_{2}\right)$ showed satisfactory results and[21] also showed that the best sterilizing agents were $3 \% \mathrm{HgCl}_{2}, 3 \% \mathrm{NaOCl}$ which reduced bacterial contaminations up to $95 \%$.

\section{Conclusion}

From the results obtained, it can be concluded that for in vitro culture of C.nocturnum nodal segments sterilization, the $(4,6 \%)$ PPM for 4 hour of constant shaking showed more effective for decontamination, survival and viability of nodal segments and shoot development. $\mathrm{HgCl}_{2}$ came second and the $\mathrm{NaOCl}$ revealed satisfactory result at high concentration.

\section{REFERENCES}

[1] Rätsch, C., The encyclopedia of psychoactive plants: ethnopharmacology and its applications. 2005: Inner Traditions/Bear \& Co.

[2] Chatterjee, S., I. Bhattacharjee, and G. Chandra, Bactericidal activities of some common herbs in India. Pharmaceutical biology, 2007. 45(5): p. 350-354.

[3] Zeng, J., X. Huang, and F. Lai, Study of local anesthetic effect of Cestrum nocturnum water extract. Gannan Yixueyuan Xuebao, 2002. 23: p. 1-3.

[4] Oyebanji, O., et al., Simple, effective and economical explant-surface sterilization protocol for cowpea, rice and sorghum seeds. African Journal of Biotechnology, 2009. 8(20).

[5] Reed, B.M., et al., Internal bacterial contamination of micropropogated hazelnut: identification and antibiotic treatment. Plant cell, tissue and organ culture, 1998. 52(1): p. 67-70.

[6] Dhingra, M., et al., Tissue culture technique for potato health, conservation, micropropagation and improvement. Tech. Bull, 1992. 39.

[7] Solfanelli, C., et al., Sucrose-specific induction of the anthocyanin biosynthetic pathway in Arabidopsis. Plant physiology, 2006. 140(2): p. 637-646.

[8] Çölgeçen, H., U. Koca, and G. Toker, Influence of different sterilization methods on callus initiation and production of pigmented callus in Arnebia densiflora Ledeb. Turkish J. Biol, 2011. 35: p. 513-520.

[9] Jain, M., et al., Embryogenic callus induction and regeneration in a pentaploid hybrid bermudagrass CV. Tifton 85. Crop science, 2005. 45(3): p. 1069-1072.

[10] Jiménez, V.M., et al., In vitro propagation of the neotropical giant bamboo, Guadua angustifolia Kunth, through axillary shoot proliferation. Plant Cell, Tissue and Organ Culture, 2006. 86(3): p. 389-395.

[11] Guri, A.Z. and K.N. Patel, Compositions and methods to prevent microbial contamination of plant tissue culture media. 1998, Google Patents.

[12] Rihan, H.Z., et al., The effect of using PPM (plant preservative mixture) on the development of cauliflower microshoots and the quality of artificial seed produced. Scientia Horticulturae, 2012. 141: p. 47-52. 
[13] Niedz, R.P., Using isothiazolone biocides to control microbial and fungal contaminants in plant tissue cultures. HortTechnology, 1998. 8(4): p. 598-601.

[14] Fuller, M. and T. Pizzey, Teaching fast and reliable plant tissue culture using PPM and Brassicas. Acta horticulturae, 2001: p. 567-570.

[15] Srivastava, N., et al., Standardization of sterilization protocol for micropropagation of Aconitum heterophyllum-An endangered medicinal herb. Academic Arena, 2010. 2(6): p. 37-42.

[16] Xu, T., et al., Efficient in vitro plant regeneration of Pinellia ternata (Thunb) Breit. Acta Biol Crac Ser Bot, 2005. 2: p. 27-32.

[17] Jan, A., et al., Surface sterilization method for reducing microbial contamination of field grown strawberry explants intended for in vitro culture. African Journal of Biotechnology, 2013. 12(39): p. 5749.

[18] Badoni, A. and J. Chauhan, In Vitro Sterilization Protocol for Micropropagation of Solanum tuberosum cv 'Kufri Himalini'. Acedemia Arena, 2010. 2(4): p. 24-28.

[19] Altaf, N., In vitro bud culture of Kinnow tree. Pakistan Journal of Botany, 2006. 38(3): p. 597.

[20] Mihaljević, I., et al., In vitro sterilization procedures for micropropagation of 'Oblačinska'sour cherry. Journal of Agricultural Sciences, Belgrade, 2013. 58(2): p. 117-126.

[21] Singh, V., et al., Identification and prevention of bacterial contimination on explant used in plant tissue culture labs. International Journal of Pharmacy and Pharmaceutical Sciences, 2011. 3(4): p. 160-163. 